\title{
Supply of medicines: paternalism, autonomy and reality
}

\author{
David Prayle and Margaret Brazier Universities of Manchester and Liverpool, and University of Manchester
}

\begin{abstract}
Radical changes are taking place in the United Kingdom in relation to the classification of, and access to, medicines. More and more medicines are being made available over the counter both in local pharmacies and in supermarkets. The provision of more open access to medicines may be hailed as a triumph for patient autonomy. This paper examines whether such a claim is real or illusory. It explores the ethical and legal implications of deregulating medicines. Do patients benefit? What is the impact on pharmacists? Are the true beneficiaries of change largely the pharmaceutical industries?

(Fournal of Medical Ethics 1998;24:93-98)
\end{abstract}

Keywords: Access to medicines; autonomy and paternalism; deregulation; pharmacy

\section{Introduction}

A silent revolution is taking place in the United Kingdom. Driven partly, though not exclusively, by European Community legislation, ${ }^{1}$ the government is re-classifying a rapidly increasing number of medicines. Medicines previously available only on prescription from a medical practitioner are now being made available in pharmacies to be bought over the counter under the supervision of a pharmacist. Medicines traditionally accessible only in pharmacies are likewise being re-classified to be included in the general sales list which allows them to be purchased in any supermarket or garage shop. Commentary on the implications of the process for health care practice has been forthcoming in medical and pharmacy journals. ${ }^{2}$ Analysis of the ethical and legal implications of change has been sparse.

A favourable response to the re-classification of medicines might be that the more freely available a medicine, the greater the autonomy of the patient. However, if we can choose to purchase medicines then we are not patients but customers. Such a superficial analysis is incomplete. The most dramatic change in the status of medicines in Britain has not yet been to make medicines entirely freely available but to allow sales of certain products in pharmacies. The pharmacist assumes the mantle of professional intermediary formerly worn in most cases by the general practitioner. Deregulation is far from wholehearted, raising no more than two cheers for autonomy.

Deregulation of medicines also prompts the question whether paternalism is necessarily all bad? Given the inherent risks of medicines, is the presence of a professional to advise and inform the layperson a prerequisite of beneficence in the supply of medicines? May professionals on occasion have a duty to restrict access to medicines and to play a role as gatekeepers as well as advisers?

This paper examines the classification of medicines in the light of European legislation. Having sketched in the background, the ethical implications of enhancing access to medicines will be explored from the perspective of patients. The impact on the legal and ethical responsibilities of professionals, primarily pharmacists, will be debated. Finally, we seek tentatively to consider whose interests really benefit from change. Are the winners patients who rejoice in an enhanced autonomy, pharmacists luxuriating in a new professional status, or the government and the pharmaceutical companies each in their own way benefiting economically from a process which it is hoped may drive down National Health Service (NHS) $\operatorname{costs}^{3}$ yet still increase the overall profit from sales of medicines? We suggest that the picture emerging from an analysis of deregulation of medicines is one of confusion.

\section{Re-classifying medicines}

The classification of medicines lies at the heart of provisions within the (British) Medicines Act 1968. Medicines are divided into three distinct categories. The primary purpose of classification is to promote the safe use of medicines. A Prescription Only Medicine (POM) can normally only be supplied on prescription after patients consult a medical practitioner. ${ }^{4}$ Medicines which are freely available to the public in any normal retail outlet are placed on the General Sales List (GSL). Such medicines will be pre-packaged items, for example, small packs of paracetamol tablets. Unusually, but not exclusively, in the 
United Kingdom ${ }^{5}$ there exists a third distinct default $^{6}$ category of medicines which may only be sold in pharmacies under the supervision of a pharmacist, Pharmacy (P) medicines. Access to $P$ medicines is therefore dependent on the supervision of a pharmacist. As with POM medicines, a professional intermediary controls the consumer's access to medicines and is available to offer expert advice on its suitability.

The classification of a medicine is set out in its product licence. ${ }^{7}$ The criteria determining a medicine's classification as POM, P or GSL include safety, efficacy, pharmacology and toxicology, the product literature available to users, data on side effects, drug interactions and any potential for abuse of the product. ${ }^{8}$ For over twenty years after the enactment of the 1968 act, British regulators adopted an extremely cautious approach to the re-classification of medicines. From 1991 a change of attitude can be detected, ${ }^{9}$ a change driven further forward by a 1992 directive from the European Community on the classification of medicines throughout the Community. ${ }^{1}$ That EC directive sets out principles governing the classification of medicines to be available with or without prescription, ${ }^{10}$ based mainly on safety grounds, but in essence having a pro-deregulation bias. The directive further requires that a mandatory five-yearly review of classification takes place, facilitated by the British regulators, who have undertaken to complete the process of reclassification within twelve months of any request from a manufacturer. ${ }^{11}$

The result of European intervention and the radically altered attitude of British regulators to categorising medicines is this: more and more medicines of greater potency are available for purchase in pharmacies and in ordinary retail outlets. ${ }^{12}$

Three principal motivations for change can be identified. First, the Pharmaceutical Society, representing and regulating pharmacists, pressed for greater availability of medicines in pharmacies, ie changes from POM to $\mathrm{P}$ status. Making more medicines available over the counter in pharmacies was perceived as an extension of the pharmacist's professional role. The society has published lists of medicines which it believes should be released to the control of the pharmacist and commentators suggest that its recommendations have carried weight. ${ }^{13}$ Paradoxically the Pharmaceutical Society more recently has expressed disquiet about the speed and extent of deregulation when medicines are given GSL status. Concern has been voiced about the rapid dual re-classification of ibuprofen, a powerful pait killer, first from POM to $\mathrm{P}$ status then from $\mathrm{P}$. GSL. ${ }^{13}$

Second, the government has sought to promote change, partly as an integral element in its genergl policy of deregulation but also to drive down costs in the NHS drug budget. When a medicine moves to $\mathbf{P}$ status it is hoped more and more patients will simply purchase the product themselves, saving the cost to the NHS of certain prescriptions and saving expensive general practitioner (GP) time $-\overrightarrow{-}$

Third, the pharmaceutical industry has obvious and powerful interest in re-classification. Increased sales of $P$ and GSL medicines can be expected, particularly as such medicines, unlike POM medicines, can be advertised to the generai public. As a number of previously profitable PON medicines reach the stage when patent protectio expires, the manufacturer must seek means of combating competition from generic copies. Altering the medicine's status to $P$ and enthusias:tically advertising the product under its tried and tested brand name is a useful strategy to maintaing if not increase, sales figures.

Many different sorts of medicines have alreact been deregulated from POM status. Poter vaginal thrush remedies and powerful antacids a now available in pharmacies. The Pharmaceutic Society has pressed for antibiotic eye-drops and creams and certain anti-emetics to move to $B$ status. ${ }^{14}$ There is a current debate about making hormonal emergency contraception available over. the counter in pharmacies. ${ }^{15} \mathrm{~A}$ brave new world of more open access to medicines beckons. Should 9 be applauded?

\section{Autonomy and access to medicines}

A restrictive approach to access to medicines restricts individual autonomy. The longer the list of POM medicines, the less able individuals are tio control their own health status via self-diagnosis and self-medication. People are compelled to seew medical assistance and doctors are empowered to control access to medication. Reducing the list POM medicines might be seen as enhancit autonomy. The flaw in this approach derives from the anomalous $\mathrm{P}$ category of medicines. ${ }^{16}$ They can be purchased, but only from a pharmac under the supervision and control of a pharmat cist. Persons seeking a P medicine must in theor submit to an interrogation from the pharmacist (or his assistant) about their familiarity with the drug, their medical history and their potential use of the product. ${ }^{17}$ This "consultation" may we take place before an audience of othe customers. ${ }^{18}$ If the pharmacist is not satisfied that 
the customer will use the medicine sought properly, he or she may, indeed must, refuse to sell.

What justification can there be for allowing a "retailer" to police his customers' purchasing habits? Two arguments may be advanced. First, it may be contended that controlling access to $P$ medicines is necessary to prevent harm to others. Second, it may be, and is, maintained that unrestricted access to medicines may endanger the customer.

Preventing harm to third parties is a well recognised ground for limiting autonomy. ${ }^{19}$ It cannot however be consistently advanced as the rationale for the $\mathbf{P}$ medicine category. Quantities of paracetamol large enough to kill have for years been available in normal retail outlets on the GSL list. Antibiotics might arguably be kept on restricted access because if antibiotics are abused and antibiotic bacterial resistance develops, our health state could endanger others. ${ }^{20}$ The vast majority of $\mathrm{P}$ medicines fall into two classes. There are medicines which are effective but carry some risk of morbidity. That risk is enhanced if the medicine is used incorrectly, either in overdose or if the customer has misdiagnosed his original condition. ${ }^{21}$ Then there are medicines where the risk of morbidity is minimal but the pharmacological efficacy may be equally minimal.

The pharmacist, it might be suggested, protects the customer from self-harm either from an inherent risk in the medicine or from buying a largely useless remedy. But why should the law intervene with such benevolent paternalism to protect the purchaser of a medicine? Rarely, other than in relation to the purchase of goods classified as medicines does the state see fit to monitor our habits so intensively and intrusively, at any rate if we are adults.

\section{Justifying moderate paternalism?}

Self-harm per se may be regarded as an insufficient justification for limiting the freedom of a person capable of making autonomous choices. Discussion of patient autonomy has, however, tended to focus on what patients may prevent health professionals doing to them rather than what they may demand that health professionals do. Evaluating the role of the pharmacist and the category of $\mathrm{P}$ medicines requires that we analyse the concept of autonomous choice of medicines, and explore the rights and interests of pharmacists themselves.

Autonomous choice depends on the provision of the necessary information on which to base that choice. People can only make maximally autonomous choices if the following conditions are met: the information requisite to make an accurate self-diagnosis is available; there is an understanding of the correct use of a product, and there is an awareness of any potential risks and side effects of available remedies. Pharmacists selling medicines are constrained by both an obligation of beneficence and non-maleficence and by respect for autonomy and should offer appropriate information. This ethical obligation as health professionals prevents the simple handing over of goods regardless of the patient's welfare.

Conventional principles of health care ethics lead fairly readily to the conclusion that pharmacists are entitled to act as professional intermediaries in the supply of medicines. Providing information and advice in no way restricts autonomy. More problematic is their role as gatekeeper of $\mathbf{P}$ medicines. Should pharmacists refuse to supply medicines to customers fully aware of the potential risks and side effects of the product and accurately informed of the dangers of misuse? Should pharmacists be empowered to question customers' self-diagnoses and deny access to medicines judged inappropriate or dangerous?

Pharmacists claim with some force that they are not simply shopkeepers but professionals. While a medicine remains on the POM list medical practitioners can prevent access to that medicine whatever the desire of their patients. The courts in England have always refused to compel doctors to act in a manner contrary to their clinical judgment as long as that judgment conforms to responsible professional practice. ${ }^{22}$ To deny the same discretion in judgment to the pharmacist is to reject the professional status of pharmacists, or at least to declare that while doctors are professionals "first class", pharmacists are professionals "second class". Moreover the very purpose of the medicines legislation which confers powers on pharmacists to restrict access to $\mathrm{P}$ medicines is to ensure professional protection of the public from dangerous medicines. Medicines, society has determined are different from other goods. The impact of illness, even minor illness, and the fears generated by ill-health result in a degree of vulnerability even on the part of a normally robust and rational person. Moderate paternalism is justifiable.

\section{Pharmacists at risk}

So far we have examined the impact of changes in the supply of medicines on patients. To understand the full implications of those changes their implications for the legal and ethical responsibilities of community pharmacists must also be explored. Pharmacists have not faced the tide of litigation against them that doctors have. ${ }^{23}$ As more and more medicines pass to their control, may the picture change? A recent survey showed 
that $25 \%$ of claims against medical practitioners related to medication errors. ${ }^{24}$ What is the legal position where injury or loss results from a $\mathrm{P}$ medicine sold over the counter?

Doctors prescribing, and pharmacists dispensing, drugs owe a duty of care to their patients. They will be held responsible if they fail to exercise their professional judgment in the provision of the medicine to the patient. Their legal obligation is to act carefully and professionally. But the pharmacist selling a medicine ${ }^{25}$ in effect and within certain limits guarantees the safety and efficacy of that product. The Sale of Goods Act 1979 implies into every business contract for the sale of goods ${ }^{26}$ (which in this context indubitably includes medicines) conditions that the goods are of satisfactory quality and fit for the purpose for which they were sold. Liability is strict. It is no answer to a claim by a person injured by an unsafe medicine sold to him that the pharmacist exercised all reasonable care in supplying the medicine. If a drug proves to be defective the pharmacist will be liable, albeit she had no means of knowing of any latent defect in the medicine supplied by her.

Exactly what that professional obligation entails in terms of contractual guarantees of fitness for purpose is difficult to tease out. Medicines are more complex than everyday goods. A young girl comes into a pharmacy and asks for a branded remedy for vaginal thrush. In fact she is suffering from a sexually transmitted disease. The pharmacist simply sells her the medicine. Was the medicine fit for the purpose? It was fit for the purpose the girl believed she needed it for but not for her true condition. A man asks for a powerful painkiller for a "hell of a hangover". He is sold ibuprofen. Unfortunately he is asthmatic and succumbs to a near fatal attack of asthma. A mother takes her child into the pharmacy. The child has a temperature of $103^{\circ}$, has been sick, and is visibly distressed. The pharmacist sells a harmless but useless cough mixture.

\section{Legal reality}

In determining exactly what the contractual "guarantee" given by the pharmacist entails, a distinction has to be drawn between useless and harmful products. Goods sold in the course of a business are required to do the job for which they are purchased. A medicine that simply did not work, or did not work for the condition which the pharmacist knew was the source of the patient's complaint would not be fit for its purpose. The patient could sue for his wasted expenditure. Such claims however will be relatively small in scale.
What of the medicine positively dangerous for that patient?

In such a case the crux of the matter becomes: given the nature of the medicine, does fitness for purpose demand that the pharmacist explore the purpose of his customer. The legal realis becomes that the guarantee inherent in the contract may for the pharmacist be little differen from his professional obligation of care. If he faifs to comply with good practice requiring that he checks that the young girl has a condition making the use of her chosen medicine appropriate, if he does not seek to ensure that the man with the hangover does not have a condition contris indicating ibuprofen, or fails to tell mum to take her child to the doctor he is negligent. $\mathrm{He}$ is in breach of his professional duty of care.

\section{Medicines Act}

What is less clear is just how far a pharmacist mu go to discharge that professional duty. Does pharmacist meet his legal obligation by seeking t provide the necessary advice and information the girl who believes mistakenly that she has thrush, to the asthmatic with the hangover and the mother of the feverish child? They may refuse to follow such advice, or angrily reject any cros examination or interference. Should pharmacist $\$$ are they required to, refuse to sell medicines whicf customers want but which they believe to be unsafe for the recipients? Will the law enforce gatekeeper role? No simple uniform answer can be given. If the medicine sought is a P medicine the it can be argued that the Medicines Act express imposes on pharmacists a responsibility to protect patients even against themselves. A court adjudit cating on a patient's claim that the pharmacis acted negligently in supplying her with the medis cine would be unlikely to find that a practice which breached the act constituted responsibse professional conduct. The patient's own conduc in insisting on being given the product migh reduce the level of compensation payable to hef by way of a plea of contributory negligence, but would not entirely exculpate the pharmacis Where a medicine is on general sale, as ibuprofem is, it is more difficult to sustain an argument that pharmacists must refuse to sell the medicine of risk liability for professional negligence. The dissatisfied customer can simply walk out of the pharmacy and buy ibuprofen at a local superma? ket. The sick child raises slightly different issue@. Does the pharmacist have a duty to the child to protect her from her mother's folly? Howeves again any enforced gatekeeper role may be futile. Mother too can simply pick up the GSL medicine from a supermarket shelf. The law, we would sug 
gest, incorporates into the pharmacist's duty of care an obligation to protect patients from unsafe or inappropriate $\mathrm{P}$ medicines, but no more than an obligation to advise patients sufficiently to protect themselves in relation to GSL medicines. It might be asked why even an obligation to advise applies to GSL medicines, given their free availability elsewhere. The answer is that in resorting to a pharmacy, rather than their local supermarket to buy medicines, patients enter the pharmacy with an expectation of receiving professional service.

\section{Theory and reality}

The very existence of a category of $P$ medicines available only in pharmacies is predicated on society conferring on pharmacists a special professional status. They are there to protect the patient even when the patient is a customer shopping for over-the-counter medicines. The law will enforce that professional obligation. That is the theory, but can reality match that theory?

$P$ medicines must be sold under the supervision of a pharmacist. The actual sale will be likely to be conducted by a sales assistant. The pharmacist will be busy in the dispensary. Protocols have been devised to ensure that in certain cases specially trained assistants can sell some $P$ medicines without even the formal assent of the pharmacist. Guidelines dictate that when approached by a customer asking for a $\mathrm{P}$ medicine the assistant should ask any questions necessary to ensure that the medicine is safe and appropriate for that customer. The substance of the professional intermediary role will rest with the assistant. The pharmacist is freed to get on with dispensing prescriptions and to fulfil a higher level advisory function.

Reality is loaded against the pharmacist and his staff. Customers may resent intrusive questioning, particularly by young sales staff. The pharmacy counter may not offer much by way of privacy and confidentiality. How many women would want to answer questions about their sexual habits or whether they might be pregnant in full hearing of other curious customers? ${ }^{27}$ Once a medicine is re-classified from POM to $P$, that medicine may be advertised. Several high-powered television campaigns have included newly re-classified $P$ medicines such as Nytol to aid sleep. These products are effectively "sold" to customers before they reach the pharmacy. Who is the assistant at the pharmacy counter to tell paying customers that it is inadvisable to use any sleeping aid more than occasionally?
The pharmacists' dilemma in reconciling theory and reality on the shopfloor is likely to be exacerbated by two current, and contradictory developments.

First, the price of licensed medicines is at present protected by a resale price maintenance agreement, that is to say, manufacturers fix a price which retailers cannot choose to undercut. In practice that means the law prohibits supermarkets cutting the price of GSL medicines so as to attract custom away from pharmacies and enhance volume sales of such products. The justification for such an anti-competitive practice has been to protect local pharmacies, not solely for the benefit of the pharmacists, but to ensure the public's continued access to professional advice on self-medication. Now an application is before the courts to abolish resale price maintenance for medicines, opening the door to competition in relation to GSL medicines and making it yet more difficult for pharmacists to fulfil an advisory function in selling medicines. ${ }^{28}$ Why pay more for a medicine and have to justify your purchase?

A second current development apparently seeks to restore some force to the pharmacist's role as protector of the public. The Medicines Control Agency (MCA), responding to concern about paracetamol overdoses, has issued for consultation proposals to limit the availability of over-thecounter painkillers by restricting pack sizes available both in pharmacies and general sales outlets. ${ }^{29}$ Such painkillers will be available on the GSL list only in packs of 12 . Up to 30 tablets will normally be available from pharmacies but pharmacists will be permitted to sell up to 100 tablets to patients with recurrent or chronic conditions, if the pharmacist judges such a sale to be appropriate.

\section{Mere functionaries}

This description proves superficial, however, when we examine paracetamol, for example. The risk of overdose is real. An overdose of 15 paracetamol tablets can cause irreversible liver damage, turning an impulsive gesture into a death sentence. Will the MCA proposal protect such vulnerable, suicidal people? ? $^{30}$ If paracetamol remains on the GSL list at all, what is to prevent such a person collecting up several packs of 12 ? Meanwhile the patient in need of the medicine and intending to use it properly has restricted access to it, and, particularly if the resale price maintenance agreement goes, must pay more for a compulsory visit to the pharmacy. Pharmacists enabled to sell more than a couple of days' supply are found again impaled on the horns of the dilemma of how far theirs is a policing rule. Can 
they effectively determine to whom it is appropriate to sell a pack of 100 tablets?

The overall impact of this picture of deregulation (and re-regulation) of medicines is that, for the most part, selling medicines is becoming increasingly commercial. Unsurprisingly customers come to perceive themselves as consumers not patients. The pharmacist, or the assistant, are mere functionaries whose task is to supply the product that customers, aided by the manufacturers' advertising agents, have determined they desire. Professional ethics fade into irrelevance. Beneficence becomes impossible to deliver. Who benefits from this brave new world? It seems doubtful that patients will. They lose a source of skilled advice on medicines, confront risks in self-medication which they may not fully comprehend and may waste money on marginally useful medicines. Pharmacists stand to lose a great deal. Reduced to mere retailers their professionalism is threatened. "Forced" to comply with demands of consumerism their pockets will ultimately suffer as litigation proliferates. The manufacturers of medicines may rejoice. Creating a climate where medicines may be marketed like any other consumer goods, profits should rise.

So the heart of the question becomes: are medicines different from other consumer goods? Why should paracetamol be policed in a way alcohol is not? Why should aspirin be treated differently from insecticide? It may be argued that the answer should be that medicines are no different from other goods. In that case the whole edifice of the regulation of medicines needs re-thinking, and concepts of professional ethics current amongst all health professionals, including pharmacists, must be converted into concepts of business ethics alone.

David Prayle, BSc(Pharm), MSc, MRPS, is a Research Fellow at the Institute of Medicine, Law and Bioethics, Universities of Manchester and Liverpool. Margaret Brazier, LLB, is a Barrister and Professor of Law at the University of Manchester and a Director of the Institute of Medicine, Law and Bioethics.

\section{References and notes}

1 Council directive 92/26/EEC. Classification for the supply of medicinal products for human use.

2 Blenkinsopp A, Bradley C. Patients, society, and the increase in self-medication. British Medical fournal 1996;312:629-32; Bond $\mathrm{CM}, \mathrm{Bradley} \mathrm{C}$. The interface between the community pharma- cist and patients. British Medical fournal 1996; 312:758-60. Th future of self-medication. Blenkinsopp A, Bradley C. Britis Medical fournal 1996;312:835-7.

3 But see doubts expressed by Maynard A, Richardson J. Over the counter medicines. Social Market Foundation occasional papef 1996.

4 See British National Formulary: exceptionally, emergenबy supplies of a POM may be made by a pharmacist at a patient request. It must be impractical to obtain a prescription an normally only a maximum of five days' supply of the medicirf may be made.

5 Canada, France, Germany and Switzerland also have three cat egories of medicines. Australia has four. In the USA there aft only two categories, the equivalent of POM and GSL, although there is support for a third. See Madahavan S. Factors influene ing pharmacists' preference for the legal classification of $\mathrm{Rx}-\mathrm{ta}$ - OTC switched drug products. Fournal of Clinical Pharmacy Therapeutics 1993;18:281-90.

6 This default category consists of medicines not listed as being GSL or POM, ie there is no list of P medicines.

7 Anonymous. POM to P Symposium: society suggests changes. Pharmaceutical fournal 1992;249:544.

8 See OTC Directory 96/97. London: Proprietary Association Great Britain.

9 See reference 2: Blenkinsopp and Bradley: 630.

10 See reference 7 . See also reference 8 and Changing the leg classification of a prescription only medicine for human use. Londow Medicines Control Agency, 1992.

11 Bradley $C$, Bond $C$. Increasing the number of medicines available over the counter: arguments for and against. Britio fournal of General Practice 1995;45:553-6.

12 See reference 2: Anonymous. Society seeks talks with MCA about GSL ibuprofen decision. Pharmaceutical fournal 1995 255: 83-9.

13 See reference 2: Blenkinsopp and Bradley: 835 .

14 See reference 7: 545 .

15 Annual Report of Royal Pharmaceutical Society 1995: 6.

16 Appelbe GE, Wingfield J. Dale and Appelbe's pharmacy, law an ethics [5th ed]. London: The Pharmaceutical Press, 1993: 64-

17 Hawksworth G. Pharmacy protocols. Pharmaceutical fourngl 1994; 253: 759-61.

18 Bond CM, Bradley C. The interface between the communi\$ pharmacist and patients. British Medical fournal 1996;312:758 60.

19 Mill JB. On liberty. In: Warnock M, ed. Utilitarianism. Londom Collins, 1972: 187.

20 Albeit there are proposals to deregulate antibiotic creams an eyedrops. See reference 18.

21 Turner, P. OTC medicines - are they open to criticism? Postgraduate Medical fournal 1987;63:s19-520.

$22 \operatorname{Re} \mathcal{f}$ (a minor) (wardship:medical treatment) [1992] 4 All E. $619, \mathrm{CA}$

23 Generally in relation to negligence in dispensing NHS prescrip. tions. See Dwyer v Roderick (1993) 127 Solicitors' fournal 806. Prendergast $v$ Sam and Dee Ltd. [1989] 1 Medical Law Repof 36.

24 Green S, Goodwin H, Moss J. Problems in general practiog London: Medical Defence Union, 1996.

25 Or supplying any medicine in pursuance of a contract for ser $\$$ ice which will include dispensing private prescriptions: Brazi\& M. Medicine, patients and the law [2nd ed]. London: Penguin, 1992: $170-1$

26 Bell A. The doctor and the Supply of Goods and Services A\&t 1982. Legal Studies $1984 ; 4: 175-84$.

27 See account of new report criticising pharmacists who failed warn customers buying Zovirax (a cold sore treatment) againso having oral sex. Anonymous. More covert research. Pharmacew
tical fournal 1994;252:3.

28 And probably driving one in four pharmacies out of busines 8 Anonymous. CPAS turns up the heat. Pharmacy Magazine 1996 Aug: 1-2.

29 Analgesic medicines available without prescription: proposed changes to product information and sale or supply of paracetamol. London Medicines Control Agency 1996 Nov 22: (MLX 231).

30 Fagen E, Wannan G. Reducing paracetamol overdoses. Briti Medical fournal 1996; 313:1417-8. 